\title{
Analisis Vegetasi Mangrove di Muara Sungai Peniti, Kabupaten Mempawah
}

\author{
Iwan Kuncoro ${ }^{1 *}$, Anthoni Batahan Aritonang ${ }^{1}$, Shifa Helena ${ }^{1}$ \\ 1 Program studi Ilmu Kelautan, FMIPA, Universitas Tanjunpura, Pontianak- \\ Indonesia \\ *Correspondence email: Iwan Kuncoro \\ $\bowtie$ iwanbahariskw@gmail.com
}

\begin{abstract}
Received:18 December 2018- Accepted: 08 January 2019
Published: 28 February 2019 @ Author(s) 2019. This article is open access
\end{abstract}

\begin{abstract}
Mangrove adalah vegetasi yang tumbuh di daerah pasang surut air laut maupun daerah muara. Salah satu muara yang terdapat di Kalimantan Barat ialah muara Sungai Peniti dengan kondisi mangrove yang masih tergolong alami dan belum pernah dilakukan penanaman. Penelitian tentang analisis vegetasi mangrove dilakukan di muara Sungai Peniti, Desa Sungai Burung Kabupaten Mempawah Provinsi Kalimantan Barat. Tujuan penelitian ini yaitu untuk mengetahui kondisi dan zonasi mangrove muara Sungai Peniti. Penentuan lokasi penelitian ditentukan dengan metode purpossive sampling, adapun dalam pengukuran dan pengamatan vegetasi mangrove dengan menggunakan metode transek. Parameter yang diamati adalah komposisi jenis, kerapatan, kerapatan relatif, frekuensi, frekuensi relatif, dominansi dan indeks nilai penting mangrove.Hasil penelitian didapat 6 jenis mangrove yaitu A. marina, A. lanata, A. alba, E. agallocha, X. mekongensis, dan N. Frutican. Nilai penting (INP) tertinggi untuk tingkat pohon ditemukan pada A. marina dengan nilai mencapai 210,12 $\%$, sedangkan pada pancang dan semai yaitu A. lanatadengan nilai penting (INP) $200 \%$. Muara sungai Peniti tidak terbentuknya suatu zonasi mangrove.
\end{abstract}

Keywords: Muara Sungai Peniti, vegetasi mangrove, zonasi mangrove

\section{Pendahuluan}

Besarnya peranan ekosistem mangrove terhadap lingkungan pesisir menjadikan mangrove sangat diperhatikan oleh banyak pihak seperti akademisi, pemerintah, maupun masyarakat sekitar. Beberapa spesies mangrove tumbuh di pesisir Kalimantan Barat, contohnya di Kabupaten Mempawah Desa Nusapati adalah Aegiceras floridum, Avicennia alba, A. lanata, A. marina, Bruguiera cylindrica, B. gymnorrhiza, $B$. parviflora, Excoecaria agallocha, Sonneratia alba, Soneratia caseolaris, dan
Xylocarpus moluccensis (Prastomo et al., 2017).

Salah satu hutan mangrove alami yang ada di Kabupaten Mempawah yaitu hutan mangrove yang terdapat di kawasan Peniti, khususnya berada di sekitar Muara Sungai Peniti, Desa Peniti Besar, Kecamatan Segedong. Hutan mangrove peniti terletak di sebelah utara Kota Pontianak. Secara geografis sungai peniti terletak antara 00011'05" LU dan 109008'14" BT dan antara 00006'13" LU dan 109009'49" BT dengan luas hutan mangrove $\pm 390,625 \mathrm{Ha}$. Lokasi penelitian berada di sekitar muara sungai peniti berjarak $\pm 2,7 \mathrm{~km}$ dari jalan 


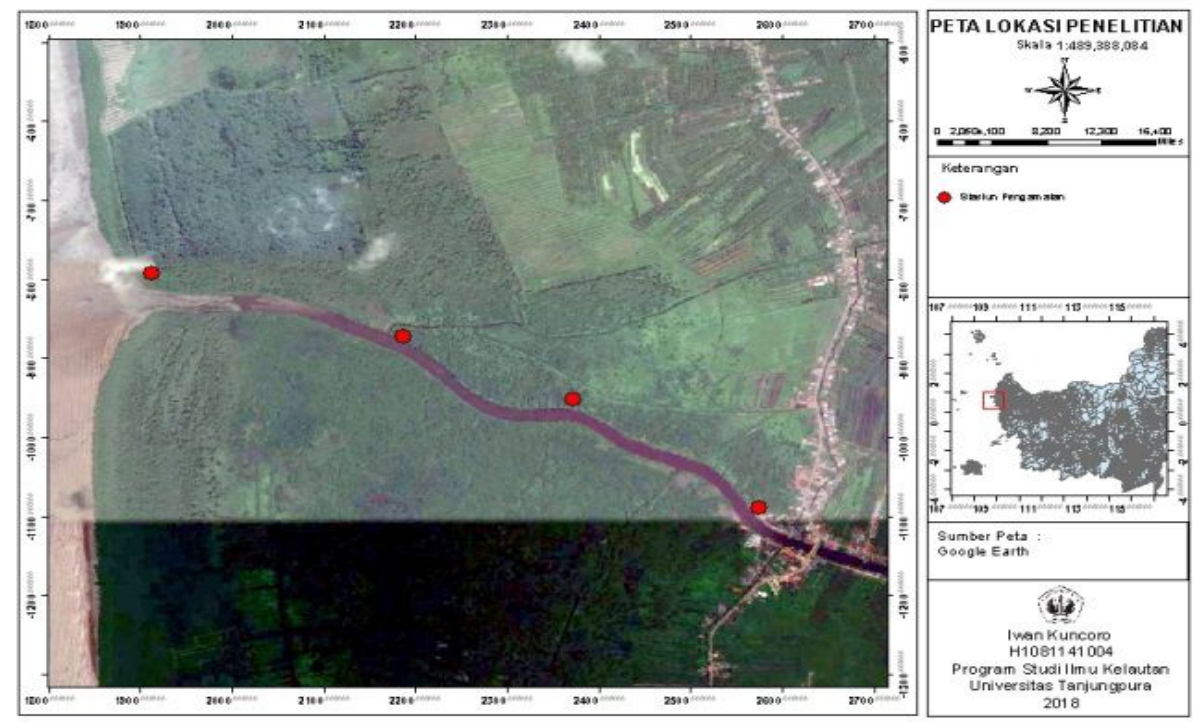

Gambar 1. Peta lokasi penelitian

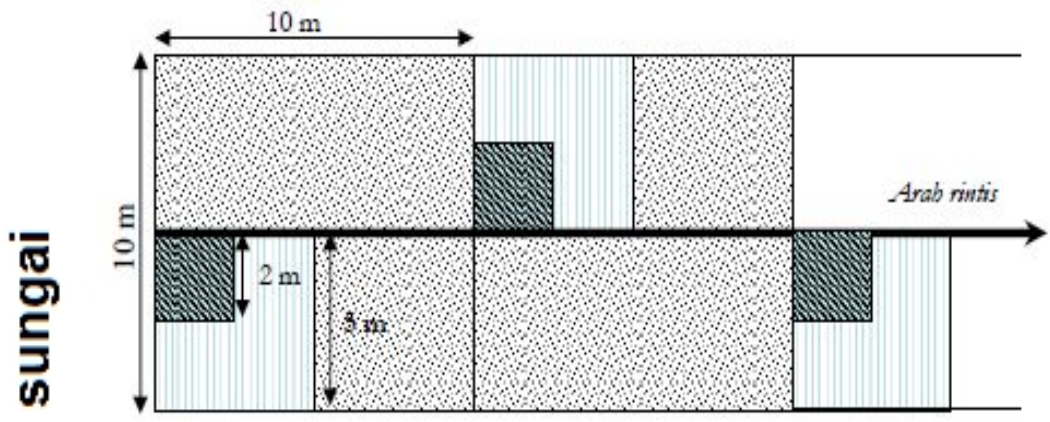

Gambar 2. Denah cara/teknik pengambilan contoh

kabupaten dan $\pm 43 \mathrm{~km}$ dari Kota Pontianak (Rudiansyah et al., 2017).

Pada umumnya seperti zonasi yang diamati pada penelitian ini, sulit ditentukan ketika sudah ada campur tangan manusia didalamnya. Minimnya informasi dan publikasi terkait kondisi maupun zonasi ekosistem mangrove di muara Sungai Peniti, maka penelitian ini dilakukan untuk mendapatkan informasi kondisi serta zonasi mangrove dengan metode purposi sampling mengacu pada penelitian yang telah dilakukan.

\section{Metode}

\subsection{Waktu dan tempat}

Penelitian telah dilaksanakan pada bulan Agustus sampai dengan Oktober 2018 di muara Sungai Peniti, Kabupaten Mempawah, Kalimantan Barat.

Penelitian ini dilakukan pada empat (4) stasiun yang berbeda seperti pada gambar 1 . Lokasi penelitian tersebut dianggap dapat mewakili kondisi hutan mangrove muara sungai Peniti, dikarenakan letak setiap stasiun yang mewakili rona lingkungan. Peletakan petak contoh dibuat dengan metode transek. Transek terdiri dari tiga plot yang disusun tegak lurus dengan sungai seperti pada gambar 2. Data yang akan diambil adalah tegakan pohon pada tingkat pertumbuhan semai, pancang dan pohon. Alat yang digunakan adalah GPS yang berfungsi untuk mengambil titik koordinat, termohigrometer untuk mengukur suhu udara, handrefraktometer untuk mengukur salinitas, rollmeter untuk mengukur panjang transek, tanur untuk mengeringkan substrat, higrometer digunakan untuk mengukur densitas substrat di laboratorium, ayakan untuk mengayak substrat,dan buku identifikasi panduan pengenalan mangrove di Indonesia oleh Noor et al. (2006).

\subsection{Pengamatan vegetasi mangrove}

Metode yang digunakan dalam penelitian ini yaitu metode purpossive sampling dengan melihat kondisi geografis dan rona 
lingkungan, dengan tujuan mengetahui zonasi yang ada di muara sungai Peniti. Metode yang digunakan dalam pengukuran dan pengamatan vegetasi mangrove adalah menggunakan metode transek atau jalur garis berpetak dengan petak berukuran $10 \times 10 \mathrm{~m}^{2}$ untuk pohon, petak dengan ukuran $5 \times 5 \mathrm{~m}^{2}$ untuk tingkat pancang, sedangkan pada petak ukuran $2 \times 2 \mathrm{~m}^{2}$ untuk tingkat semai (Onrizal, 2008).

Keterangan :

1. Petak ukur $10 \mathrm{~m} \times 10 \mathrm{~m}$ untuk tingkat pohon dengan diameter $10 \mathrm{~cm}$ atau lebih

2. Petak ukur $5 \mathrm{~m} \times 5 \mathrm{~m}$ untuk tingkat pancang dengan diameter kurang dari 10 $\mathrm{cm}$ dan tinggi $1,5 \mathrm{~m}$

3. Petak ukur $2 \mathrm{~m} \times 2 \mathrm{~m}$ untuk tingkat semai dengan tinggi kurang dari $1,5 \mathrm{~m}$

Parameter data yang dikumpulkan adalah jenis mangrove, jumlah individu tiap jenis (pohon, pancang, dan semai), diameter batang atau DBH (diamater at breast height), jenis substrat, dan parameter fisik-kimia lainnya seperti suhu, dan salinitas (Alik et al., 2012).

Parameter lingkungan yang diambil ialah subsrat, salinitas yang diambil dengan refraktometer, suhu udara dengan termohigrometer, $\mathrm{pH}$ dengan $\mathrm{pH}$ meter, dengan 3 kali pengulangan.

\subsection{Pengolahan Data}

Data yang didapat dari lapangan diolah dengan menggunakan program microsoft excel.

Kerapatan $(D)$ memberikan gambaran jumlah individu dalam plot. Nilai dari kerapatan dapat dihitung dengan menggunakan rumus :

$$
\begin{aligned}
& D=\frac{n_{i}}{A} \\
& R d_{i}(\%)=\frac{n i}{\sum n i} \times 100 \%
\end{aligned}
$$

Dimana $n i$ adalah jumlah individu dalam satu spesies, $A$ adalah luas area dalam satuan $\mathrm{m}^{2}$, $\Sigma n i$ adalah jumlah individu seluruh spesies, dan $R d_{i}$ adalah kerapatan relatif.

Frekuensi $\left(F_{i}\right)$ jenis adalah suatu nilai yang menunjukkan penyebaran dari suatu jenis dalam plot. Nilai ini didapat dengan rumus :

$$
F_{i}=\frac{p_{i}}{\sum p}
$$

$R F_{i}=\frac{F_{i}}{\sum F} \times 100 \%$

Dimana $p_{i}$ adalah banyak petak ditemukannya jenis $i, p$ adalah banyaknya seluruh petak, $F_{i}$ adalah frekuensi jenis $i$, dan $\sum F$ adalah frekuensi dari seluruh petak, $R F_{i}$ adalah frekuensi relatif.

Dominansi (dominancy) memberikan gambaran tentang penguasaan jenis dalam plot. Nilai ini didapat dengan rumus :

$C_{i}=\frac{\sum B A}{A}$

$R C_{i}=\frac{c_{i}}{\sum C} \times 100 \%$

Dimana $\sum B A$ adalah jumlah area basal suatu jenis individu, $A$ adalah jumlah seluruh sampel area, $C_{i}$ adalah tutupan jenis $i$, $\sum C$ adalah jumlah tutupan seluruh jenis.

Indeks Nilai Penting (Importance Value) merupakan nilai penguasaan masing-masing jenis vegetasi di suatu daerah. Nilai penting dihitung dengan rumus sebagai berikut :

INP tingkat pancang dan pohon:

$$
I N P=R D_{i}+R F_{i}+R C_{i}
$$

INP tingkat semai

$I N P=R D_{i}+R F_{i}+R C_{i}$

Dengan :

$R D_{i}=$ Kerapatan Relatif

$R F_{i}=$ Frekuensi Relatif

$R C_{i}=$ Dominansi Relatif

\section{Hasil dan Pembahasan}

\subsection{Komposisi Vegetasi Mangrove}

Pada penelitian yang telah dilakukan untuk komposisi vegetasi mangrove diperoleh 6 (enam) jenis vegetasi mangrove yang termasuk kedalam 4 famili. Jenis-jenis mangrove yang diidentifikasi secara keseluruhan dapat dilihat pada Tabel 1.

Hasil penelitian Habdiansyah et al. (2015) di kecamatan Paloh, kabupaten Sambas mendapatkan 4 spesies mangrove, lebih sedikit dibandingkan dengan hasil yang didapat dari muara Sungai Peniti. Beberapa penelitian di lokasi lainnya menunjukkan spesies mangrove yang didapat lebih banyak dibanding muara Sungai Peniti, seperti pada 
Tabel 1. Spesies mangrove yang ditemukan di lokasi penelitian

\begin{tabular}{|c|c|c|c|c|}
\hline No & Nama Species & Family & Habitus & $\begin{array}{c}\text { Kelompok } \\
\text { Mangrove }\end{array}$ \\
\hline 1 & Avicennia marina & Avicenniaceae & Pohon & Mayor \\
\hline 2 & Avicennia lanata & Avicenniaceae & Pohon & Mayor \\
\hline 3 & Avicennia alba & Avicenniaceae & Pohon & Mayor \\
\hline 4 & Excoecaria agallocha & Euphorbiaceae & Pohon & Minor \\
\hline 5 & Xylocarpus mekongensis & Meliaceae & Pohon & Minor \\
\hline 6 & Nypa frutican & Arecaceae & Pohon & Mayor \\
\hline 7 & Acanthus ilicifolius & Acanthaceae & Semak & Mayor \\
\hline
\end{tabular}

Tabel 2. Hasil Analisis Vegetasi Mangrove pada Tingkat Semai

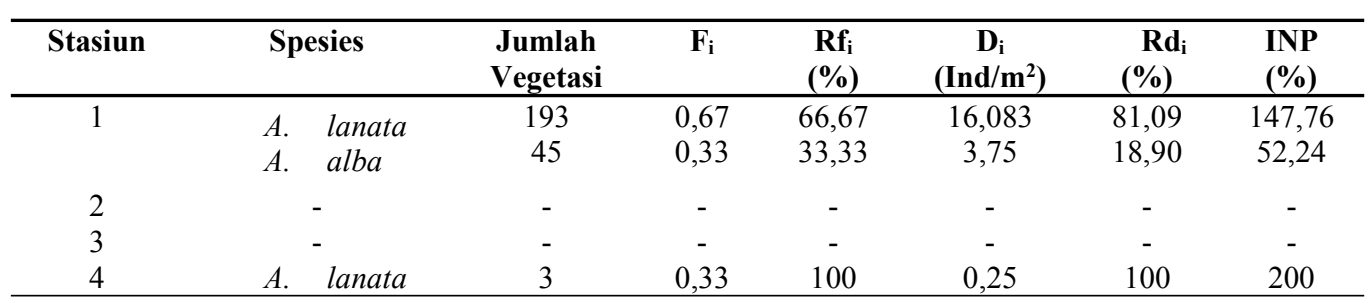

hasil penelitian Nurrahman et al. (2012) ditemukan 8 spesies mangrove, kemudian penelitian Marini et al. (2018) mendapatkan 10 spesies mangrove di Desa Sungai Bakau Kecil, kabupaten Mempawah.

\subsection{Struktur Komunitas Vegetasi Mangrove}

Struktur komunitas vegetasi mangrove dapat diketahui dengan cara menentukan indeks nilai penting.

\subsubsection{Tingkat Semai}

Hasil analisis Kerapatan jenis, Kerapatan relatif, Frekuensi jenis, Frekuensi relatif, dan Indeks Nilai Penting mangrove tingkat semai di muara sungai Peniti, Kabupaten Mempawah memiliki nilai yang berbeda pada setiap jalur pengamatan. Hasil perhitungan Kerapatan jenis, Kerapatan relatif, Frekuensi jenis, Frekuensi relatif dan Indeks Nilai Penting mangrove tingkat semai dapat dilihat pada Tabel 2.Jumlah mangrove pada tingkat semai terbanyak ditemukan pada spesies $A$. Lanata yang ditemukan pada stasiun 1 (satu) dengan jumlah 193 individu dengan frekuensi sebesar 0,67. Spesies pada tingkatan pancang dengan kerapatan tertinggi ialah A. lanata dengan nilai $16,083 \mathrm{ind} / \mathrm{m}^{2}$.

Dari Tabel 2, terlihat vegetasi mangrove tingkat semai di muara sungai Peniti menunjukkan di ketiga stasiun sampling lebih didominasi oleh genus Avicenniaceae. Ini menunjukkan di lokasi ini memiliki karakteristik habitat yang baik untuk tumbuh dan berkembang didukung oleh substrat berlumpur yang mampu menahan semaian dari terjangan ombak (pada stasiun 1). Kerapatan mangrove tertinggi tingkat semai yaitu $A$. lanata dengan nilai kerapatan 16,083 ind $/ \mathrm{m}^{2}$. Hal ini menunjukkan bahwa jenis $A$. lanata memiliki kemampuan dan kesesuaian untuk tumbuh dan berkembang dengan baik. Diantara 4 stasiun pengamatan, dua stasiun diantaranya stasiun 2 dan 3 tidak ditemukan adanya semaian, pada stasiun tersebut lebih sering ditemukan mangrove A. ilicifolius (Jeruju) berupa semak sehingga menutupi lahan terbuka yang ada. Tutupan mangrove $A$. ilicifolius di dasar hutan mempengaruhi kerapatan maupun frekuensi vegetasi mangrove tingkat semai, ini dikarenakan kurangnya penyerapan cahaya matahari oleh vegetasi tingkat semai sehingga semaikurang dapat tumbuh dengan baik.

\subsubsection{Tingkat pancang}

Struktur vegetasi mangrove ditingkat pancang, disajikan pada Tabel 3 .

Jenis mangrove pada tingkat pancang juga didominasi oleh genus Avicenniaceae, dengan ditemukannya pada 3 stasiun pengamatan kecuali stasiun 3. Jenis yang hanya ditemukan pada stasiun 3 yaitu $N$. frutican tidak tergolong dalam tingkatan pancang. Jenis $A$. lanata memiliki nilai penting (INP) yang tinggi pada stasiun 4 , hal ini menunjukkan tingkat adaptasi Avicennia 
Tabel 3. Hasil Analisis Vegetasi Hutan Mangrove Pada Tingkat Pancang

\begin{tabular}{|c|c|c|c|c|c|c|c|c|c|}
\hline Stasiun & Spesies & $\begin{array}{l}\text { Jumlah } \\
\text { Vegetasi } \\
\end{array}$ & $\overline{F_{i}}$ & $\mathbf{R} \mathbf{f}_{\mathbf{i}}$ & $\begin{array}{r}D_{\mathbf{i}} \\
\left(\text { Ind } / \mathbf{m}^{2}\right) \\
\end{array}$ & $\mathbf{R d}_{\mathrm{i}}$ & $\begin{array}{c}D \\
\left(m^{2} / h a\right) \\
\end{array}$ & $\begin{array}{l}\text { DR } \\
(\%)\end{array}$ & $\begin{array}{l}\text { INP } \\
(\%) \\
\end{array}$ \\
\hline 1 & $\begin{array}{l}\text { A. lanata } \\
\text { A. alba }\end{array}$ & $\begin{array}{l}1 \\
20\end{array}$ & $\begin{array}{l}0,33 \\
0,67\end{array}$ & $\begin{array}{l}33,33 \\
66,67\end{array}$ & $\begin{array}{l}0,013 \\
0,27\end{array}$ & $\begin{array}{l}4,76 \\
95,24\end{array}$ & $\begin{array}{l}0,51 \\
7,86\end{array}$ & $\begin{array}{r}6,14 \\
93,86\end{array}$ & $\begin{array}{c}38,1 \\
161,90\end{array}$ \\
\hline 2 & $\begin{array}{l}\text { A. alba } \\
\text { X. mekongensi }\end{array}$ & is & $\begin{array}{l}0,33 \\
0,67\end{array}$ & $\begin{array}{l}33,33 \\
66,67\end{array}$ & $\begin{array}{l}0,013 \\
0,04\end{array}$ & $\begin{array}{l}25 \\
75\end{array}$ & $\begin{array}{l}0,18 \\
0,56\end{array}$ & $\begin{array}{l}24,36 \\
75,64\end{array}$ & $\begin{array}{c}58,33 \\
141,67\end{array}$ \\
\hline $\begin{array}{l}3 \\
4\end{array}$ & $\begin{array}{l}\text { N. frutican } \\
\text { A. lanata }\end{array}$ & - & $0,-$ & $\begin{array}{l}- \\
100\end{array}$ & $\begin{array}{l}- \\
0.053\end{array}$ & $\begin{array}{l}- \\
100\end{array}$ & - & $100^{-}$ & $\begin{array}{c}- \\
200\end{array}$ \\
\hline
\end{tabular}

Tabel 4. Hasil Analisis Vegetasi Hutan Mangrove pada Tingkat Pohon

\begin{tabular}{clcccccccc}
\hline Stasiun & Spesies & $\begin{array}{r}\text { Jumlah } \\
\text { Vegetasi }\end{array}$ & $\mathbf{F}_{\mathbf{i}}$ & $\begin{array}{c}\mathbf{R f}_{\mathbf{i}} \\
\mathbf{( \% )}\end{array}$ & $\begin{array}{c}\mathbf{D}_{\mathbf{i}} \\
\left(\mathbf{I n d} / \mathbf{m}^{2}\right)\end{array}$ & $\begin{array}{c}\mathbf{R d}_{\mathbf{i}} \\
\mathbf{( \% )}\end{array}$ & $\begin{array}{c}\mathbf{D} \\
\left(\mathbf{m}^{\mathbf{2}} / \mathbf{h a}\right)\end{array}$ & $\begin{array}{c}\mathbf{D R} \\
\mathbf{( \% )}\end{array}$ & $\begin{array}{c}\mathbf{I N P} \\
\mathbf{( \% )}\end{array}$ \\
\hline \multirow{2}{*}{1} & A.marina & 2 & 0,67 & 66,67 & 0,0067 & 66,67 & 1,48 & 76,79 & 210,12 \\
& A.alba & 1 & 0,33 & 33,33 & 0,0033 & 33,33 & 0,45 & 23,22 & 89,88 \\
2 & A.marina & 1 & 0,33 & 16,67 & 0,0033 & 7,69 & 0,80 & 4,53 & 28,89 \\
& A.lanata & 2 & 0,33 & 16,67 & 0,0067 & 15,39 & 5,76 & 32,45 & 64,50 \\
& A.alba & 9 & 1 & 50 & 0,03 & 69,23 & 8,02 & 45,24 & 164,47 \\
\multirow{2}{*}{3} & E.agallocha & 1 & 0,33 & 16,67 & 0,0033 & 7,69 & 3,15 & 17,78 & 42,14 \\
4 & N.frutican & 19 & 1 & 100 & 0,063 & 100 & $*$ & $*$ & 200 \\
& A.lanata & 5 & 0,67 & 40 & 0,0167 & 38,46 & 11,60 & 67,80 & 146,27 \\
& A.marina & 1 & 0,33 & 20 & 0,0033 & 7,69 & 0,54 & 3,14 & 30,83 \\
& X.mekongensis & 7 & 0,67 & 40 & 0,023 & 53,85 & 4,97 & 29,06 & 122,90 \\
\hline
\end{tabular}

yang baik di stasiun 4. Pada tingkatan pancang di stasiun 1 dan 4, kerapatan tinggi pada genus Avicenniaceae menunjukkan bahwa komunitas vegetasi tersebut berada pada kondisi yang tidak mengalami gangguan (Fadli, 2014)

\subsubsection{Tingkat pohon}

Struktur vegetasi tingkat pohon disajikan pada Tabel 4. Stasiun 1 merupakan stasiun yang berhadapan dengan laut, vegetasi mangrove tingkat pohon pada stasiun 1 didominasi oleh $A$. marina, hal ini menunjukkan bahwa $A$. marina sangat adaptif terhadap kondisi dengan salinitas yang tinggi. Avicennia merupakan genus yang memiliki kemampuan toleransi terhadap kisaran salinitas yang luas dibandingkan dengan genus lainnya.

A. marina mampu tumbuh dengan baik pada salinitas yang mendekati tawar sampai dengan 90\%o (Susanto, 2011). Hal ini juga disebabkan karena penyebaran biji jenis $A$. marina merata di zona depan yang memiliki kandungan substrat berlumpur agak lembek yang mendukung pertumbuhan dan kerapatan jenis A. marina pada tingkat semai dan pancang, sehingga kerapatan tingkat semai dan pancang lebih tinggi dari jenis mangrove yang lain (Hotden, 2013). Pernyataan tersebut kurang relevan jika dikaitkan dengan hasil penelitian yang didapat pada muara sungai Peniti. Spesies $A$. Marina tidak ditemukan dalam tingkatan semai dan pancang, hal ini dikarenakan adanya faktor tumbuhan jeruju yang mendominasi di beberapa stasiun sehingga mengganggu proses pertumbuhan spesies $A$. marina.

Stasiun 2 didominasi oleh $A$. alba dengan nilai penting (INP) sebesar 164, $47 \%$. Stasiun 3 didominasi oleh N. frutican, hal ini dikarenakan adanya pengaruh sainitas yang kurang sehingga $N$. frutican dapat tumbuh dengan baik. Tanaman tumbuh rapat bersama, seringkali membentuk komunitas murni yang luas di sepanjang sungai dekat muara hingga sungai dengan air payau (Kitamura et al., 1997). Stasiun 4 masih ditemukan adanya genus Avicennia, dikarenakan substrat yang sesuai sehingga memungkinkan pertumbuhannya dengan baik walau dengan kadar salinitas yang tidak terlalu tinggi. Menurut Saparinto (2007), mangrove bergantung pada air laut (pasang), air tawar, dan endapan lumpur sebagai sumber hara. Berdasarkan hasil vegetasi yang didapat, tidak terbentuknya zonasi pada muara Sungai 
Tabel 5. Faktor Hutan Mangrove di Kawasan Muara Sungai Peniti, Kabupaten Mempawah

\begin{tabular}{lcccc}
\hline Data & Stasiun 1 & Stasiun 2 & Stasiun 3 & Stasiun 4 \\
\hline Salinitas (ppt) & 24,7 & 15 & 14 & 9 \\
Suhu Udara $\left({ }^{\circ} \mathrm{C}\right)$ & 27 & 28 & 28,6 & 29 \\
pH & 7,27 & 6,8 & 6,6 & 6,3 \\
\multirow{2}{*}{ Jenis Substrat } & Tanahliat & Tanahliat & Tanahliat & Tanahliat \\
& berlanau & berlanau & berlanau & berlanau \\
\hline
\end{tabular}

Peniti. Informasi terkait zonasi mangrove didapat dari hasil vegetasi yang didapat dari setiap stasiun pengamatan. Hal ini dikarenakan adanya faktor manusia yaitu penebangan hutan yang dilakukan pada saat pembukaan lahan industri, namun pembanguan industri tersebut hingga kini belum terealisasikan. Akibat adanya penebangan hutan yang dilakukan berdampak pada menurunnya keanekaragaman spesies yang ada di muara Sungai Peniti. Hal ini karena menurunnya jumlah vegetasi yang akan berdampak pada keanekaragaman spesies yang ada.

\subsection{Parameter Lingkungan}

Adapun parameter lingkungan yang diukur ditampilkan pada Tabel 5. Faktor - Faktor Lingkungan muara sungai Peniti.

Salinitas pada muara sungai Peniti berkisar 14 sampai dengan 24,7 ppt. Salinitas tertinggi berada pada stasiun 1 dikarenakan berhadapan dengan laut. Semakin tinggi tingkat salinitas maka pertumbuhan tanaman akan semakin terganggu (Keliat et al., 2015).

Nilai $\mathrm{pH}$ dari setiap stasiun diperoleh kisaran antara 6,3 hingga 7,27. Kisaran nilai ini masih dalam batas toleransi pertumbuhan mangrove, secara umum mangrove dapat hidup pada $\mathrm{pH}$ berkisar antara 5,0-8,5. Substrat yang ada dilokasi penelitian termasuk kelas substrat tanah liat berlanau atau lempung berdebu. Sifat khas yang dimiliki oleh tanah lempung adalah dalam keadaan kering akan bersifat keras.

Family Avicenniaceae tidak hanya mendominasi di stasiun 1, melainkan ditemukan juga pada stasiun 2 dan 4 . Hal ini menunjukkan bahwa family tersebut mempunyai kemampuan dan daya adaptasi terhadap lingkungan tempat tumbuhnya dengan baik. Berdasarkan hasil, stasiun 1 hingga Stasiun 4 memiliki substrat yang serupa yaitu liat berlanau, yang membedakan setiap stasiun ialah tingkat lunak atau kerasnya. Stasiun 1 bersifat lunak karena berhadapan dengan laut dan tergenang jika pasang, sedangkan stasiun ke 2 hingga ke 4 semakin mengeras substratnya.

\section{Kesimpulan}

Berdasarkan analisis penelitian struktur vegetasi mangrove di muara sungai Peniti Kabupaten Mempawah, maka dapat ditarik kesimpulan bahwa:

- Komposisi vegetasi hutan mangrove yang ada di muara Sungai Peniti terdiri dari 6 (enam) jenis vegetasi yaitu $A$. marina, A. alba, A. lanata, E. agallocha, $X$. mekongensis, dan $N$. frutican.

- Tidak terbentuknya zonasi mangrove pada muara sungai Peniti, dikarenakan faktor lingkungan yang tidak dapat mendukung tumbuhnya Rhizopora dengan baik.

- Faktor-faktor lingkungan yang mempengaruhi diantaranya salinitas dengan kisaran 9-24,7 ppt, suhu udara dengan kisaran $27-29\left({ }^{\circ} \mathrm{C}\right)$, dan $\mathrm{pH}$ antara 6,3-7,27.

\section{Ucapan Terima Kasih}

Penulis mengucapkan terimakasih kepada pihak Community Development and Outreaching Universitas Tanjungpura yang telah memberikan bantuan beasiswa kepada penulis sehingga dapat menyelesaikan studi S1, maupun kepada semua pihak yang terlibat secara langsung maupun tidak dari penelitian ini hingga telah didapatkan hasil yang semoga bermanfaat bagi akademisi maupun penggiat pesisir.

\section{Daftar Pustaka}

Alik, T.S.D., M.R. Umar, and D. Priosambodo. 2012. Analisis Vegetasi Mangrove Di Pesisir Pantai Mara'bombang - Kabupaten Pinrang. ---. ---.

Fadli, Khairijon, and N. Sofiyanti. 2014. Analisis Vegetasi Avicennia Sp. dan Karakteristik Sedimen Di Kawasan Mangrove Desa Sungai 
Rawa Kecamatan Sungai Apit Kabupaten Siak, Riau. ---. ----.

Habdiansyah, P., I. Lovadi, and R. Linda. 2015. Profil Vegetasi Mangrove Desa Sebubus Kecamatan Paloh Kabupaten Sambas, $J$. Protobiont. 4(2):9-17.

Hotden, Khairijon, and M.N. Isda. 2013. Analisis Vegetasi Mangrove Di Ekosistem Mangrove Desa Tapian Nauli I Kecamatan Tapian Nauli Kabupaten Tapanuli Tengah Provinsi Sumatera Utara. JOM FMIPA. 1.

Kitamura, S., C. Anwar, A. Chaniago, S. Baba. 1997. Handbook of Mangroves in Indonesia-Bali and Lombok. Depertement of Sustanable Mangrove Project.

Marini, A.A. Kushadiwijayanto, and Y.A. Nurrahman. 2018. Struktur Komunitas Hutan Mangrove di Desa Sungai Bakau Kecil Kabupaten Mempawah Kalimantan Barat. Jurnal Laut Khatulistiwa. 1(3):73-80.

Nurrahman, Y.A., O.S. Djunaedi, and R. Rostika. 2012. Struktur dan Komposisi Vegetasi Mangrove di Pesisir Kecamatan Sungai Raya Kepulauan Bengkayang Kalimantan Barat. $J$. Perikanan dan Kelautan. 3(1):99-107.

Onrizal. 2008. Panduan Pengenalan dan Analisis Vegetasi Hutan Mangrove. Sumatera Utara: Departemen Kehutanan, Universitas Sumatera Utara.

Prastomo, R.H., R. Herawatiningsih, and S. Latifah. 2017. Keanekaragaman Vegetasi di Kawasan Hutan Mangrove Desa Nusapati Kabupaten Mempawah. Jurnal Hutan Lestari. 5(2):556-562.

Rudiansyah, D., Rahmawati, and Rafdinal. 2017. Eksplorasi Bakteri Selulolitik dari Tanah Hutan Mangrove Peniti, Kecamatan Segedong, Kabupaten Mempawah. J. Protobiont. 6(3):255-262.

Saparinto, C. 2007. Pendayagunaan Ekosistem Mangrove. Semarang: Penerbit Dahara Prize.

Susanto, A.H, T. Soedarti, and H. Purnobasuki. 2011. Struktur Komunitas Mangrove Di Sekitar Jembatan Suramadu Sisi Surabaya. ---.---. 